\title{
Success Rates of Clomiphene Citrate and Recombinant Gonadotropin Cycles: A Single-Center Experience
}

\author{
Beril GURLEK ${ }^{1}$, Ali Sertac BATIOGLU², Mine Kanat PEKTAS ${ }^{3}$, Ibrahim KALE ${ }^{4}$, Ozgur ONAL 5 , \\ Nafiye YILMAZ KARAKAS ${ }^{6}$
}

Rize, Turkey

\begin{abstract}
OBJECTIVE: This aim of this study is to assess the ovulation induction cycles based on clomiphene citrate and gonadotropin administration and specify the factors associated with successful outcomes.

STUDY DESIGN: This is a prospective study of 631 patients who underwent 917 ovulation induction cycles. While clomiphene citrate was used in 680 cycles $(74.2 \%)$ and recombinant follicle-stimulating hormone was administered in 237 cycles (25.8\%).

RESULTS: A total of 153 pregnancies were achieved in 917 ovulation induction cycles, indicating a clinical pregnancy rate of $16.7 \%$. The ovulation induction cycles which ended up with clinical pregnancy had a significantly lower frequency of smoking $(p=0.005)$, shorter infertility duration $(p=0.001)$, higher basal luteinizing hormone $(p=0.021)$ and lower basal progesterone $(p=0.008)$ than unsuccessful cycles. The clomiphene citrate cycles which ended up with clinical pregnancy had a significantly lower frequency of smoking $(p=0.011)$, shorter infertility duration $(p=0.001)$ and lower basal progesterone $(p=0.013)$ than the unsuccessful cycles. The recombinant follicle-stimulating hormone cycles which ended up with clinical pregnancy had a significantly higher basal luteinizing hormone $(p=0.008)$ than the unsuccessful cycles. Basal luteinizing hormone and progesterone concentrations could significantly distinguish the patients who were able to conceive in ovulation induction cycles ( $p=0.021$ and $p=0.008$, respectively).
\end{abstract}

CONCLUSIONS: Smoking, longer duration of infertility, and elevated basal progesterone are poor prognostic factors for clinical pregnancy in clomiphene citrate and recombinant follicle-stimulating hormone cycles.

Keywords: Clomiphene, Follicle-stimulating hormone, Ovulation induction, Pregnancy, Progesterone

Gynecol Obstet Reprod Med 2020;26(1):31-37

${ }^{1}$ Department of Obstetrics and Gynecology, Recep Tayyip Erdogan University Faculty of Medicine, Rize

Department of Obstetrics and Gynecology, Usak University Faculty of Medicine, Usak

3 Department of Obstetrics and Gynecology, Afyon Kocatepe University Faculty of Medicine, Afyonkarahisar

${ }^{4}$ Department of Obstetrics and Gynecology, Umraniye Training and Research Hospital, Istanbul

Department of Public Health, Suleyman Demirel University Faculty of Medicine, Isparta

${ }^{6}$ Department of Reproductive Endocrinology, Zekai Tahir Burak Women's Health and Research Hospital, Ankara

Address of Correspondence: Beril Gurlek

Department of Obstetrics and Gynecology, Recep Tayyip Erdogan University Faculty of Medicine, Islampasa, 53020, Rize, Turkey beril.gurlek@erdogan.edu.tr

Submitted for Publication: Revised for Publication: Accepted for Publication: ORCID IDs of the authors: ASB:0000-0001-7349-6463,

IK:0000-0001-7802-7199,

NYK: 0000-0002-4041-297X

15.05.2019

10.07.2019

23.07.2019

BG:0000-0002-4050-3193,

$M K P: 0000-0003-2862-3288$

OO:0000-0001-6514-2120

\begin{tabular}{|c|c|}
\hline \multirow{3}{*}{ 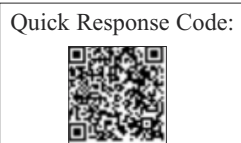 } & Access this article online \\
\hline & $\begin{array}{l}\text { Website: www.gorm.com.tr } \\
\text { e- mail: info@gorm.com.tr }\end{array}$ \\
\hline & DOI:10.21613/GORM.2019.978 \\
\hline
\end{tabular}

How to cite this article: Gurlek B. Batioglu AS. Pektas MK. Kale I. Onal O. Yilmaz Karakas N. Success Rates of Clomiphene Citrate and Recombinant Gonadotropin Cycles: A Single-Center Experience. Gynecol Obstet Reprod Med 2020;26(1):31-37

\section{Introduction}

Infertility is a public health concern that drives many couples to search for the help of assisted reproductive technology (ART) methods. In vitro, fertilization has been addressed as the most successful ART procedure, but it is relatively expensive and less available. Therefore, less invasive and more affordable procedures such as ovulation induction and intrauterine insemination (IUI) have become popular (1-3).

Clomiphene citrate (CC) has been traditionally used as the first-line drug for ovulation induction in women with chronic anovulation. Gonadotropins are an alternative, especially for women with $\mathrm{CC}$ resistance. However, the optimal choice that combines optimal effectiveness, safety, and costs are subject to debate. Although ovarian stimulation aims to achieve multifollicular growth in women with unexplained infertility, mono-follicular growth appears to be sufficient for women who are to undergo ovulation induction due to chronic anovulation. Various success rates have been yielded for various populations of infertile couples, $30 \%$ percent of the total pregnancy rates have been reported for ovulation induction cycles followed by IUI (3-5). 
The infertile couples undergoing ovulation induction cycles are keen to know their chances of success as they are most likely to have emotional distress. Thus, it would be prudent to determine the factors favoring pregnancy in ovulation induction cycles $(6,7)$. The factors associated with the success of ovulation induction cycles have been identified as female age, type, and duration of infertility, the number of mature follicles recruited and endometrial thickness (8-10). Although results usually compromise with some of these factors, there is still a lack of consistency in terms of other factors such as sex hormones.

This aim of this study is to assess the ovulation induction cycles based on CC and gonadotropin administration and specify the factors associated with successful outcomes.

\section{Material and method}

The present study was approved by the Ethical Committee of Dr. Zekai Tahir Burak Research Hospital (Approval no: 10), where it was undertaken between March 2008 and April 2010. The study protocol was undertaken in accordance with the principles of the Declaration of Helsinki and all participants gave their written informed consent. This is a prospective evaluation of 631 patients who underwent 917 ovulation induction cycles at Department of Reproductive Endocrinology, Zekai Tahir Burak Women's Health and Research Hospital, Ankara, Turkey.

Clomiphene citrate was used for ovulation induction in 680 cycles $(74.2 \%)$, and recombinant follicle-stimulating hormone (rFSH) was administered for ovulation induction in 237 cycles $(25.8 \%)$.

The women with one-year-long primary infertility and sixmonth-long secondary infertility were included in this study. The women aged $\geq 40$ years, the women with body mass index (BMI) $>29.9 \mathrm{~kg} / \mathrm{m}^{2}$, the women with poor ovarian reserve (with antral follicles of less than 5 to 7), the women who underwent ovarian and/or tubal surgery or with bilateral tubal factor, the women with male infertility, the women with endometriosis, women with uterine factor (fibroids, polyps and malformations), the women with systemic chronic diseases and women with endocrinopathies (diabetes mellitus, thyroid dysfunction, hyperprolactinemia, Cushing syndrome and lateonset congenital adrenal hyperplasia) were excluded.

Body mass index (BMI) was calculated as follows:

Body mass index $\left(\mathrm{kg} / \mathrm{m}^{2}\right)=$ Body weight $(\mathrm{kg}) /$ Height $^{2}\left(\mathrm{~m}^{2}\right)$

\section{Ovulation Induction}

Basal serum follicle-stimulating hormone (FSH), luteinizing hormone $(\mathrm{LH})$, estradiol, and progesterone levels were measured on day 3 of the menstrual cycle by automated Elecsys Immunoanalyser (Roche Diagnostics, Mannheim, Germany). The intra-assay and inter-assay coefficients of vari- ation $(\mathrm{CVs})$ were $<3 \%$ and $<6 \%$ for $\mathrm{FSH},<3 \%$ and $<4 \%$ for $\mathrm{LH},<5 \%$ and $<10 \%$ for estradiol and $<3 \%$ and $5 \%$ for progesterone. Moreover, endometrial thickness and antral follicle count were evaluated on day 3 by transvaginal ultrasonography.

Ovulation induction by was begun on day 3 of the menstrual cycle. was given orally at a dose of 50 to $150 \mathrm{mg} /$ day for five days. Ovulation induction by $\mathrm{rFSH}$ was begun at an initial subcutaneous dose of 50-100 IU/day 3 of the menstrual cycle. The rFSH dose was modified by the follicular growth, endometrial thickening, and serum estradiol levels. When at least one mature follicle reached a diameter of at least $18 \mathrm{~mm}$ in ovulation induction cycles, ovulation triggering was performed by intramuscular administration of 10000U IU human chorionic gonadotropin. None of the patients underwent a session of IUI.

The ovulation induction cycles were canceled if there were no mature follicles, more than four mature follicles were monitored, or serum estradiol concentrations were above 2000 $\mathrm{ng} / \mathrm{mL}$.

A clinical pregnancy is defined by the presence of an intrauterine embryo with a heartbeat, whereas an ongoing pregnancy was defined as a normally developing and living embryo beyond 12 weeks.

\section{Statistical Analysis}

Collected data were analyzed by Statistical Package for Social Sciences version 18.0 (SPSS IBM, Armonk, NY, USA). Continuous variables were expressed as mean \pm standard deviation (range: minimum-maximum), and categorical variables were denoted as numbers or percentages where appropriate. Normally distributed continuous variables were analyzed by the independent samples t-test, and categorical variables were analyzed by Fisher's exact test. Receiver operating characteristic (ROC) curves were drawn to specify the predictive power of early follicular phase hormones ( $\mathrm{FSH}, \mathrm{LH}$, estradiol, and progesterone), endometrial thickness and antral follicle count in distinguishing between the patients who were able to conceive and those who were unable. Two-tailed $\mathrm{p}$ values less than 0.05 , with a confidence level of $95 \%$ were accepted to be statistically significant.

\section{Results}

Table I summarizes the demographic and clinical characteristics of groups with and without clinical pregnancy after ovulation induction. A total of 153 pregnancies occurred in 917 ovulation induction cycles, indicating a clinical pregnancy rate of $16.7 \%$. Compared to unsuccessful ovulation induction cycles, the cycles ending up with pregnancy had a significantly lower frequency of smoking ( $p=0.005)$, shorter infertility duration $(p=0.001)$, higher basal LH $(p=0.021)$, and lower basal progesterone $(p=0.008)$. 
Table I: Demographic and clinical characteristics of groups with and without clinical pregnancy after ovulation induction

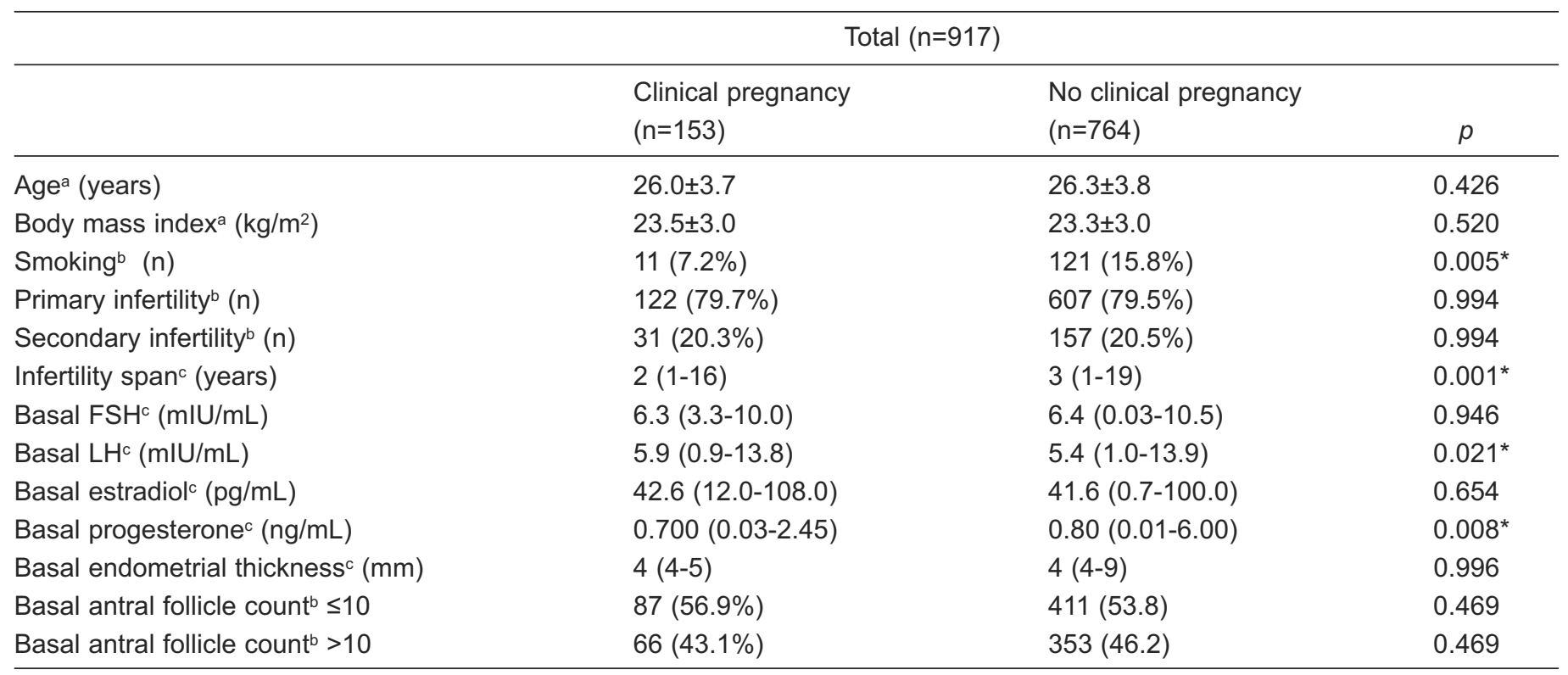

FSH: Follicle-stimulating hormone, IUI: Intrauterine insemination, LH: Luteinizing hormone. a:Data were shown as mean \pm standard deviation,

$b$ : As the number of cases and (\%), ${ }^{c}$ : As the median (minimum-maximum). ${ }^{*} p<0.05$ was accepted to be statistically significant.

Table II demonstrates the demographic, clinical characteristics and pregnancy outcomes of patients assigned to receive either CC or rFSH for ovulation induction. When compared to the women in the CC group, the women in the rFSH group had significantly older age $(p=0.001)$, higher BMI $(p=0.002)$, higher incidence of primary infertility $(p=0.005)$, longer infertility $\operatorname{span}(p=0.001)$, lower basal LH $(p=0.001)$, and lower cycle cancellation rates $(p<0.001)$. Clinical and ongoing pregnancy rates were statistically similar between groups.
Table III displays the demographic and clinical characteristics of groups with and without clinical pregnancy after ovulation induction with $\mathrm{CC}$ or rFSH. When compared to unsuccessful $\mathrm{CC}$ cycles, the $\mathrm{CC}$ cycles ending up with pregnancy had a significantly lower frequency of smoking $(p=0.011)$, shorter infertility duration $(p=0.001)$, and lower basal progesterone $(p=0.013)$. The patients who conceived after $\mathrm{rFSH}$ treatment had significantly higher basal LH $(p=0.008)$ compared to the patients who were unable to conceive after $\mathrm{rFSH}$ treatment.

Table II: Demographic, clinical characteristics, and pregnancy outcomes of patients assigned to receive either clomiphene citrate or recombinant follicle-stimulating hormone for ovulation induction

\begin{tabular}{|c|c|c|c|}
\hline & $\begin{array}{l}\text { Recombinant FSH } \\
(n=237)\end{array}$ & $\begin{array}{l}\text { Clomiphene citrate } \\
(n=680)\end{array}$ & $p$ \\
\hline Age $^{a}$ (year) & $27.4 \pm 3.7$ & $25.8 \pm 3.7$ & $<0.001^{*}$ \\
\hline Body mass index $\left(\mathrm{kg} / \mathrm{m}^{2}\right)$ & $23.9 \pm 3.0$ & $23.2 \pm 3.0$ & $0.002^{*}$ \\
\hline Smoking $^{\mathrm{b}}(\mathrm{n})$ & $34(14.3 \%)$ & $98(14.4 \%)$ & 0.980 \\
\hline Infertility spanc (years) & $5(1-19)$ & $3(1-17)$ & $<0.001^{*}$ \\
\hline Primary infertility (n) & $204(86.1 \%)$ & $525(77.2 \%)$ & $0.005^{*}$ \\
\hline Secondary infertility $(n)$ & $33(13.9 \%)$ & $155(22.8 \%)$ & $0.005^{*}$ \\
\hline Basal FSHc (mIU/mL) & $6.4(2.4-10.5)$ & $6.3(0.03-10.1)$ & 0.296 \\
\hline Basal LHc (mlU/mL) & $4.8(1.0-13.9)$ & $5.6(0.86-13.9)$ & $<0.001^{*}$ \\
\hline Basal progesteronec $(\mathrm{ng} / \mathrm{mL})$ & $0.77(0.08-4.68)$ & $0.8(0.01-6.0)$ & 0.294 \\
\hline Basal estradiolc (pg/mL) & $40(12-100)$ & $42.3(0.7-108)$ & 0.120 \\
\hline Basal endometrial thickness ${ }^{\mathrm{c}}(\mathrm{mm})$ & $4(4-6)$ & $4(4-9)$ & 0.608 \\
\hline Basal antral follicle count ${ }^{b} \leq 10(n)$ & $138(58.2 \%)$ & $360(52.9)$ & 0.196 \\
\hline Basal antral follicle count ${ }^{b}>10(n)$ & $99(41.8 \%)$ & $320(47.1)$ & 0.196 \\
\hline Cycle cancellation ${ }^{b}(\mathrm{n})$ & $18(7.6 \%)$ & $121(17.8)$ & $<0.001^{*}$ \\
\hline Clinical pregnancy ${ }^{b}(n)$ & $37(15.6 \%)$ & $116(17.1)$ & 0.607 \\
\hline Ongoing pregnancy $(n)$ & $31(13.0 \%)$ & $107(17.5 \%)$ & 0.439 \\
\hline
\end{tabular}

FSH: Follicle-stimulating hormone, IUI: Intrauterine insemination, LH: Luteinizing hormone, a: Data were shown as mean \pm standard deviation,

${ }^{b}$ : As the number of cases and (\%), ${ }^{c}$ : As the median (minimum-maximum). ${ }^{*} p<0.05$ was accepted to be statistically significant. 
Table III: Demographic and clinical characteristics of groups with and without clinical pregnancy after ovulation induction with clomiphene citrate or recombinant follicle-stimulating hormone

\begin{tabular}{|c|c|c|c|c|c|c|}
\hline & \multicolumn{3}{|c|}{ Clomiphene citrate $(n=680)$} & \multicolumn{3}{|c|}{ Recombinant FSH $(n=237)$} \\
\hline & $\begin{array}{l}\text { Clinical } \\
\text { pregnancy } \\
(n=115)\end{array}$ & $\begin{array}{l}\text { No clinical } \\
\text { pregnancy } \\
(n=565)\end{array}$ & $p$ & $\begin{array}{l}\text { Clinical } \\
\text { pregnancy } \\
(n=38)\end{array}$ & $\begin{array}{l}\text { No clinical } \\
\text { pregnancy } \\
(n=199)\end{array}$ & $\mathrm{p}$ \\
\hline Age $^{a}$ (years) & $25.8 \pm 3.6$ & $25.9 \pm 3.8$ & 0.837 & $26.8 \pm 3.9$ & $27.6 \pm 3.7$ & 0.279 \\
\hline $\mathrm{BMl}^{\mathrm{a}}\left(\mathrm{kg} / \mathrm{m}^{2}\right)$ & $23.2 \pm 2.9$ & $23.2 \pm 3.0$ & 0.964 & $24.5 \pm 3.1$ & $23.8 \pm 3.0$ & 0.185 \\
\hline Smoking (n) & $8(6.9 \%)$ & $9016.0 \%)$ & $0.011^{*}$ & $3(8.1 \%)$ & $31(15.5 \%)$ & 0.239 \\
\hline Primary infertility ${ }^{\mathrm{b}}(\mathrm{n})$ & $87(75.0 \%)$ & $438(77.7 \%)$ & 0.444 & $35(94.6 \%)$ & $169(84.5 \%)$ & 0.092 \\
\hline Secondary infertility ${ }^{b}(n)$ & $29(25.0 \%)$ & $126(22.3 \%)$ & 0.444 & $2(5.4 \%)$ & $31(15.5 \%)$ & 0.092 \\
\hline Infertility spanc (years) & $2(1-16)$ & $3(1-17)$ & $0.001^{*}$ & $3(1-15)$ & $5(1-19)$ & 0.055 \\
\hline Basal FSH ${ }^{\mathrm{c}}(\mathrm{mlU} / \mathrm{mL})$ & $6.3(3.3-10)$ & $6.3(0.03-10.1)$ & 0.647 & $6.3(3.8-10.0)$ & $6.5(2.4-10.5)$ & 0.359 \\
\hline Basal LHc (mlU/mL) & $5.8(0.9-13.8)$ & $5.6(1.3-13.9)$ & 0.270 & $6.1(1.9-13.4)$ & $4.7(1.0-13.9)$ & $0.008^{*}$ \\
\hline Basal estradiolc $(\mathrm{pg} / \mathrm{mL})$ & $42.7(13.4-108)$ & $42.2(0.7-100)$ & 0.382 & $40(12-100)$ & $40.1(13-94.8)$ & 0.596 \\
\hline Basal PGc $(n g / m L)$ & $0.7(0.03-2.4)$ & $0.8(0.01-6.0)$ & $0.013^{*}$ & $0.7(0.08-1.6)$ & $0.8(0.2-4.7)$ & 0.287 \\
\hline Basal ETc $(\mathrm{mm})$ & $4(4-5)$ & $4(4-9)$ & 0.864 & $6.3(3.8-10.0)$ & $6.5(2.4-10.5)$ & 0.359 \\
\hline Basal AFC ${ }^{b} \leq 10$ & $65(56.0 \%)$ & $295(52.3 \%)$ & 0.399 & $22(59.5 \%)$ & $116(58.0 \%)$ & 0.990 \\
\hline Basal AFC ${ }^{b}>10$ & $51(44.0 \%)$ & $269(47.7 \%)$ & 0.399 & $15(40.5 \%)$ & $84(42.0 \%)$ & 0.990 \\
\hline
\end{tabular}

BMI: Body mass index, AFC: Antral follicle count, ET: Endometrial thickness, FSH: Follicle-stimulating hormone, IUI: Intrauterine insemination, LH: Luteinizing hormone, PG: Progesterone, a: Data were shown as mean \pm standard deviation, ${ }^{b}$ : As the number of cases and (\%), c: As the median (minimum-maximum). ${ }^{*} p<0.05$ was accepted to be statistically significant.

Figure 1 indicates that the ROC curve drawn for basal LH had a significantly larger area with a cut-off point of 5.56 $\mathrm{mIU} / \mathrm{mL}$ (AUC: 0.559; $95 \%$ confidence interval: 0.509-0.610; $p=0.021)$.

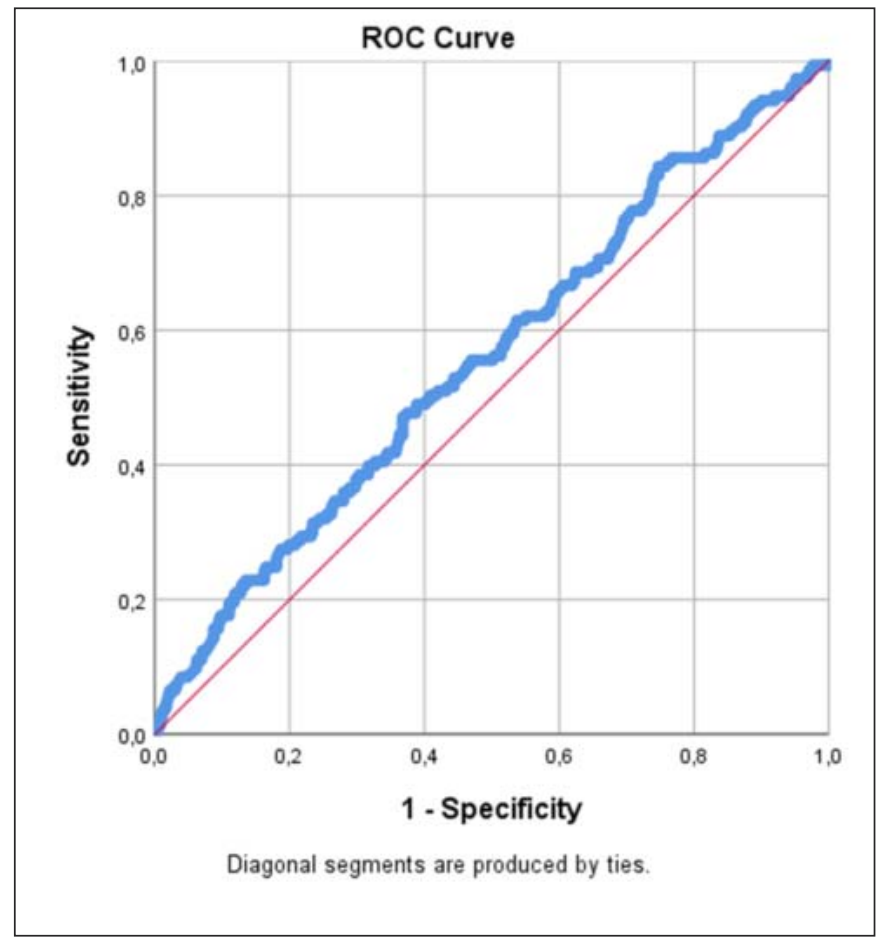

Figure 1: Receiver operating characteristic curves of serum luteinizing hormone concentration on day 3 of the menstrual cycle for predicting pregnancy
Figure 2 shows that the ROC curve drawn for basal progesterone had a significantly larger area with a cut-off point of $0.642 \mathrm{ng} / \mathrm{mL}$ (AUC: 0.568 ; $95 \%$ confidence interval: 0.518 $0.618 ; p=0.008)$. That is, basal LH and progesterone concen-

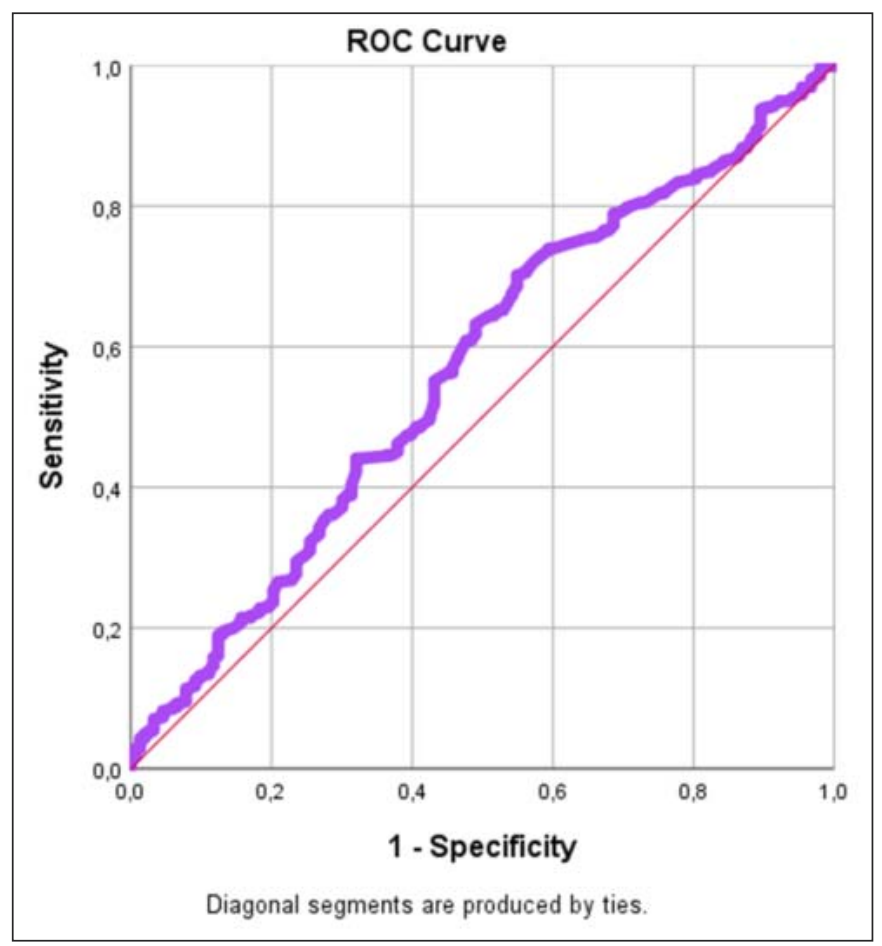

Figure 2: Receiver operating characteristic curves of serum progesterone concentration on day 3 of the menstrual cycle for predicting pregnancy 
trations could significantly distinguish the patients who were able to conceive in ovulation induction cycles.

\section{Discussion}

According to a Cochrane review published in 2007, rFSH is the drug of choice for ovarian stimulation in women undergoing IUI (11). This meta-analysis of seven studies examining 556 women showed significantly higher pregnancy rates for rFSH when compared to $\mathrm{CC}$ (Odds ratio $=1.8,95 \% \mathrm{CI}$ : $1.2-$ 2.7) (11). A randomized controlled trial published in 2015 also indicated significantly higher live birth rates for $\mathrm{rFSH}$ when compared to CC in IUI cycles (12).

On the other hand, Danhof et al. claimed that they had adequate power to show that there is no statistically significant difference between $\mathrm{rFSH}$ and $\mathrm{CC}$ in IUI cycles with respect to cumulative ongoing pregnancy rates (Absolute rate difference $=0.04$, 95\% CI:-0.02 to 0.11) (9). Similarly, Huang et al. concluded that $\mathrm{CC}$ and gonadotropins were equally efficient and safe in PCOS patients who are to undergo IUI after ovulation induction (10). In that study, clinical pregnancy rates were computed as $17.7 \%$ vs $17.5 \%$ for CC and gonadotropin cycles, respectively (10).

Accordingly, this study found $\mathrm{CC}$ and rFSH similarly effective for achieving clinical pregnancy in ovulation induction cycles $(15.6 \%$ vs $17.1 \%$, respectively). It was found that multi-follicular growth did not increase live birth rates, but significantly increased multiple pregnancy rates from $0.8 \%$ to $15.5 \%$ (10). A meta-analysis by van Rumste pointed out that multiple pregnancy rate was increased without a substantial gain in overall pregnancy rate whenever multi-follicular growth was achieved in ovulation induction-IUI cycles (13). The findings of the present study suggest that $\mathrm{CC}$ cycles might have outcomes that are as favorable as those of rFSH cycles. This unexpected result may be due to the significantly younger age, lower BMI, shorter infertility duration and higher secondary infertility rate of the women who underwent ovulation induction by $\mathrm{CC}$ administration.

Cigarette smoke contains several toxic chemical compounds which induce oxidative stress. Due to the enhancement in oxidative stress, smoking women have significantly higher basal FSH, lower serum anti-Müllerian hormone (AMH) and lower oocyte fertilization, which exerts a negative impact on ovarian reserve in in-vitro fertilization (IVF) cycles (14-16). In parallel, the results of this study indicate that ovulation induction cycles ending up with clinical pregnancy have a significantly lower frequency of smoking.

On the other hand, Farhi and colleagues did not identify significant differences in pregnancy rates of smokers and nonsmokers $(16.3 \%$ and $15.8 \%$, respectively) in a retrospective review of 885 couples undergoing IUI after ovulation induction. However, a higher dose of gonadotropins was required in smokers (17). Another analysis of 900 couples with unexplained infertility was unable to detect a correlation between smoking and live birth in ovulation induction-IUI cycles (18). Similarly, a Turkish study was unable to address female smoking as a predictive factor for clinical pregnancy in the first IUI cycles (19). These discrepant results might be attributed to the relatively small number of smoking women, lack of longitudinal data and heterogeneity in studied populations.

Duration of infertility also affects the success of ovulation induction cycles $(20,21)$. Jeon et al. assessed 348 IUI cycles using CC or letrozole combined with gonadotropins, or gonadotropins only and described the longer duration of infertility as an unfavorable factor for clinical pregnancy in IUI cycles (20). The longer duration of infertility has also been associated with lower clinical pregnancy and live birth rates in couples with unexplained infertility (18). A study evaluating Turkish couples with unexplained infertility and mild male infertility concluded that the clinical pregnancy rate was positively affected by a shorter duration of infertility (21). Complying with literature, ovulation induction cycles achieving the clinical pregnancy have a significantly shorter duration of infertility than unsuccessful cycles in this study. It is prudent to expect better outcomes in ovulation induction cycles of couples with shorter infertility span as the factors affecting these couples are probably less severe.

It has been hypothesized that incomplete destruction of a preceding corpus luteum and excessive production within the adrenal gland can lead to an early elevation of serum progesterone before ovulation. This premature rise of progesterone might force the endometrium to advance earlier, disturb synchronization between endometrium and transferred embryos and, thus, affect endometrial receptivity in IVF cycles (22, 23). Kolibianakis et al. were the first to find that the ongoing pregnancy rate was significantly lower in IVF cycles with elevated basal progesterone levels (24). Blockeel et al. used gonadotropin-releasing hormone $(\mathrm{GnRH})$ antagonist for 3 days in cycles with elevated basal progesterone $(>1.5 \mathrm{ng} / \mathrm{mL})$ so that these women had statistically similar clinical pregnancy rates (25). Hamdine et al. also concluded that there was a lower chance of achieving an ongoing pregnancy in case of early basal progesterone rise (>1.5 ng/dL) (26). In contrast, Mutlu et al. were unable to specify an association between basal progesterone levels and pregnancy outcomes. They argued that canceling cycles with elevated basal progesterone might be the underlying reason (27).

As for the present study, ovulation induction cycles ending up with clinical pregnancy had significantly lower basal progesterone than unsuccessful cycles. Moreover, progesterone concentrations $<0.642 \mathrm{ng} / \mathrm{mL}$ could distinguish the patients who were able to conceive in ovulation induction cycles. However, the detection of a significant difference for basal progesterone did not correspond to a meaningful clinical im- 
plication. This incompetency can be attributed to the relatively small cohort size as well as the relatively higher cycle cancellation rates in both $\mathrm{CC}$ and $\mathrm{rFSH}$ cycles.

In conclusion, smoking, longer duration of infertility and elevated basal progesterone appear to be related to failure to conceive in ovulation induction cycles. However, this conclusion should be considered carefully as the power of this study is limited by several factors, including relatively small cohort size, and the lack of randomization, longitudinal data, and data related to AMH levels. Further research is warranted to clarify the factors associated with the success of $\mathrm{CC}$ and gonadotropin use in anovulatory women undergoing ovulation induction.

Acknowledgment: This research received no specific grant from any funding agency in the public, commercial, or not-forprofit sectors.

Funding: There is no sponsorship or financial support in our work.

Conflict of Interests: No potential conflict of interest was reported by the authors.

Authors Contributions: BG: Study conceptualization and protocol planning, supervision, clinical data collection and manuscript writing/editing. ASB:Study conceptualization and protocol planning, supervision. MK: Clinical data collection and manuscript writing/editing. IK: Clinical data collection. OO: Clinical data analysis. NYK: Study conceptualization and protocol planning, supervision.

The authors alone are responsible for the content and writing of the paper.

\section{References}

1. Kushnir VA, Barad DH, Albertini DF, Darmon SK, Gleicher N. Systematic review of worldwide trends in assisted reproductive technology 2004-2013. Reprod Biol Endocrinol. 2017;15(1):6.

2. Farquhar C, Rishworth JR, Brown J, Nelen WL, Marjoribanks J. Assisted reproductive technology: an overview of Cochrane Reviews. Cochrane Database Syst Rev. 2013;8:CD010537.

3. Toner JP, Coddington CC, Doody K, Van Voorhis B, Seifer DB, Ball GD, et al. Society for Assisted Reproductive Technology and assisted reproductive technology in the United States: a 2016 update. Fertil Steril. 2016;106(3):541-6.

4. Von Hofe J, Bates GW. Ovulation induction. Obstet Gynecol Clin North Am. 2015;42(1):27-7.

5. Li RH, $\mathrm{Ng}$ EH. Management of anovulatory infertility. Best Pract Res Clin Obstet Gynaecol. 2012;26(6):757-68.

6. Weiss NS, Schreurs AMF, van der Veen F, Hompes PGA, Lambalk CB, Mol BW, et al. Women's perspectives on ovulation induction with or without IUI as a treatment for normogonadotrophic anovulation: a discrete choice experiment. Hum Reprod Open. 2017;2017(3):hox021.
7. Kahyaoğlu S, Yılmaz B, Işık AZ. Pharmacokinetic, pharmacodynamic, and clinical aspects of ovulation induction agents: A review of the literature. J Turk Ger Gynecol Assoc. 2017;18(1):48-55.

8. Oduola OO, Ryan GA, Umana E, Conway U, Purandare $\mathrm{N}$. Ovulation induction comparing success rates between anovulatory and ovulatory cycles using different treatment protocols. Gynecol Endocrinol. 2019:1-3.

9. Huang S, Du X, Wang R, Li R, Wang H, Luo L, et al. Ovulation induction and intrauterine insemination in infertile women with polycystic ovary syndrome: A comparison of drugs. Eur J Obstet Gynecol Reprod Biol. 2018;231:117-21.

10. Danhof NA, van Wely M, Repping S, Koks C, Verhoeve HR, de Bruin JP, et al. Follicle stimulating hormone versus clomiphene citrate in intrauterine insemination for unexplained subfertility: a randomized controlled trial. Hum Reprod. 2018;33(10):1866-74.

11. Cantineau AE, Cohlen BJ, Heineman MJ. Ovarian stimulation protocols (anti-estrogens, gonadotrophins with and without GnRH agonists/antagonists) for intrauterine insemination (IUI) in women with subfertility. Cochrane Database Syst Rev. 2007;(2):CD005356.

12. Diamond MP, Legro RS, Coutifaris C, Alvero R, Robinson RD, Casson P, et al. Letrozole, Gonadotropin, or Clomiphene for Unexplained Infertility. N Engl J Med. 2015;373(13):1230-40.

13. van Rumste MM, Custers IM, van der Veen F, van Wely M, Evers JL, Mol BW. The influence of the number of follicles on pregnancy rates in intrauterine insemination with ovarian stimulation: a meta-analysis. Hum Reprod Update. 2008;14(6):563-70.

14. Soares SR, Simon C, Remohí J, Pellicer A. Cigarette smoking affects uterine receptiveness. Hum Reprod. 2007;22(2):543-7.

15. Farhi J, Ben-Haroush A, Lande Y, Fisch B. Role of treatment with ovarian stimulation and intrauterine insemination in women with unilateral tubal occlusion diagnosed by hysterosalpingography. Fertil Steril. 2007;88(2):396400 .

16. Firns S, Cruzat VF, Keane KN, Joesbury KA, Lee AH, Newsholme P, et al. The effect of cigarette smoking, alcohol consumption and fruit and vegetable consumption on IVF outcomes: a review and presentation of original data. Reprod Biol Endocrinol. 2015;13:134.

17. Farhi J, Orvieto R. Influence of smoking on outcome of $\mathrm{COH}$ and IUI in subfertile couples. J Assist Reprod Genet. 2009;26(7):421-4.

18. Hansen KR, He AL, Styer AK, Wild RA, Butts S, Engmann L, et al. Predictors of pregnancy and live-birth in couples with unexplained infertility after ovarian stimulation-intrauterine insemination. Fertil Steril. 2016; 105(6):1575-83.e2. 
19. Aydin Y, Hassa H, Oge T, Tokgoz VY. Factors predictive of clinical pregnancy in the first intrauterine insemination cycle of 306 couples with favourable female patient characteristics. Hum Fertil (Camb). 2013;16(4):286-90.

20. Jeon YE, Jung JA, Kim HY, Seo SK, Cho S, Choi YS, et al. Predictive factors for pregnancy during the first four intrauterine insemination cycles using gonadotropin. Gynecol Endocrinol. 2013;29(9):834-8.

21. Atasever M, Kalem MN, Hatırnaz Ş, Hatırnaz E, Kalem Z, Kalaylığlu Z. Factors affecting clinical pregnancy rates after IUI for the treatment of unexplained infertility and mild male subfertility. J Turk Ger Gynecol Assoc. 2016;17(3):134-8.

22. Venetis CA, Kolibianakis EM, Bosdou JK, Tarlatzis BC. Progesterone elevation and probability of pregnancy after IVF: a systematic review and meta-analysis of over 60000 cycles. Hum Reprod Update. 2013;19(5):433-57.

23. Bosch E, Labarta E, Crespo J, Simón C, Remohí J, Jenkins $\mathrm{J}$, et al. Circulating progesterone levels and ongoing pregnancy rates in controlled ovarian stimulation cycles for in vitro fertilization: analysis of over 4000 cycles. Hum
Reprod. 2010;25(8):2092-100.

24. Kolibianakis EM, Zikopoulos K, Smitz J, Camus M, Tournaye H, Van Steirteghem AC, et al. Elevated progesterone at initiation of stimulation is associated with a lower ongoing pregnancy rate after IVF using GnRH antagonists. Hum Reprod. 2004;19(7):1525-9.

25. Blockeel C, Baumgarten M, De Vos M, Verheyen G, Devroey P. Administration of GnRH antagonists in case of elevated progesterone at initiation of the cycle: a prospective cohort study. Curr Pharm Biotechnol. 2011;12(3): 423-8.

26. Hamdine O, Macklon NS, Eijkemans MJ, Laven JS, Cohlen BJ, Verhoeff A, et al. Elevated early follicular progesterone levels and in vitro fertilization outcomes: a prospective intervention study and meta-analysis. Fertil Steril. 2014;102(2):448-54.

27. Mutlu MF, Erdem M, Mutlu I, Bulut B, Erdem A. Elevated basal progesterone levels are associated with increased preovulatory progesterone rise but not with higher pregnancy rates in ICSI cycles with GnRH antagonists. Eur J Obstet Gynecol Reprod Biol. 2017;216:46-50. 